\title{
Morbidity and mortality among very preterm singletons following fertility treatment in Australia and New Zealand, a population cohort study
}

\author{
Alex Y Wang ${ }^{1 *}$, Abrar A. Chughtai ${ }^{2}$, Kei Lui ${ }^{3}$ and Elizabeth A. Sullivan ${ }^{1}$
}

\begin{abstract}
Background: Due to high rates of multiple birth and preterm birth following fertility treatment, the rates of mortality and morbidity among births following fertility treatment were higher than those conceived spontaneously. However, it is unclear whether the rates of adverse neonatal outcomes remain higher for very preterm ( $<32$ weeks gestational age) singletons born after fertility treatment. This study aims to compare adverse neonatal outcomes among very preterm singletons born after fertility treatment including assisted reproductive technology (ART) hyper-ovulution (HO) and artificial insemination (Al) to those following spontaneous conception.

Methods: The population cohort study included 24069 liveborn very preterm singletons who were admitted to Neonatal Intensive Care Unit (NICU) in Australia and New Zealand from 2000 to 2010. The in-hospital neonatal mortality and morbidity among 21753 liveborn very preterm singletons were compared by maternal mode of conceptions: spontaneous conception, HO, ART and Al. Univariate and multivariate binary logistic regression analysis was used to examine the association between mode of conception and various outcome factors. Odds ratio (OR) and adjusted odds ratio (AOR) and 95\% confidence interval (Cl) were calculated.
\end{abstract}

Results: The rate of small for gestational age was significantly higher in $\mathrm{HO}$ group (AOR 1.52, 95\% Cl 1.02-2.67) and Al group (AOR 2.98, 95\% Cl 1.53-5.81) than spontaneous group. The rate of birth defect was significantly higher in ART group (AOR 1.71, 95\% Cl 1.36-2.16) and Al group (AOR 3.01, 95\% Cl 1.47-6.19) compared to spontaneous group. Singletons following ART had 43\% increased odds of necrotizing enterocolitis (AOR 1.43, 95\% Cl 1.04-1.97) and $71 \%$ increased odds of major surgery (AOR 1.71,95\% Cl 1.37-2.13) compared to singletons conceived spontaneously. Other birth and NICU outcomes were not different among the comparison groups.

Conclusions: Compared to the spontaneous conception group, risk of congenital abnormality significantly increases after ART and Al; the risk of morbidities increases after ART, HO and Al. Preconception planning should include comprehensive information about the benefits and risks of fertility treatment on the neonatal outcomes.

Keywords: Preterm birth, Very preterm birth, Assisted reproductive technology, Hyper-ovulation, Artificial insemination

\footnotetext{
* Correspondence: alex.wang@uts.edu.au

${ }^{1}$ Faculty of Health, University of Technology Sydney, PO Box 123, Broadway,

NSW 2007, Australia

Full list of author information is available at the end of the article
} 


\section{Background}

The latest report of Australia's mothers and babies shows that 25113 of the 301810 babies (8.3\%) born in Australia in 2012 were preterm $(<37$ weeks gestational age), the most common cause of death among infants [1]. Worldwide, around 14.9 million babies were born preterm in 2010 (11.1\% of total birth in the same year). Of these, about $5 \%$ were extreme preterm ( $<28$ weeks), $11 \%$ were very preterm (28-31 weeks gestational age) and $84 \%$ moderate to late preterm (32-36 weeks gestational age) [2]. In comparison, of preterm births in Australia in 2012, 11\% were extreme preterm, 9\% were very preterm and $80 \%$ were moderate to late preterm [1]. Evidence shows that extreme preterm and very preterm births are at increased risk of severe morbidity and mortality compared to moderate preterm births (32-36 weeks) and term births ( $>36$ weeks) [3].

With the advanced care in neonatal intensive care units (NICU), the survival of very preterm babies has been improved in recent years, especially in developed countries. The 2012 annual report by the Australian and New Zealand Neonatal Network (ANZNN) shows that the survival rate before NICU discharge was $70 \%$ for births of 24 weeks gestational age and $98 \%$ for births of 31 weeks gestational age [4]. The ANZNN data also shows that the NICU survival rates varied by plurality, with significantly higher survival rates for singletons than for multiples.

The literature suggests that multiple birth is the most significant risk factor of preterm birth and subsequent adverse neonatal outcome [5]. Preterm birth occurred in $60.8 \%$ of twins and in $94.8 \%$ of higher order multiple births compared to $6.9 \%$ of singletons [1]. The neonatal death rates of twins (10.9 per 1,000 live births) and higher order multiples (28.7 per 1,000 live births) were significantly higher than that of singletons ( 2.1 per 1,000 live births) [1]. Given the higher rate of multiple pregnancy following assisted reproductive technology (ART), births following ART were at increased risk of preterm birth and subsequent adverse neonatal outcomes. Previous studies also reported increased morbidity and mortality among births following ART compared to those following spontaneous conception [6, 7]. However, it is unclear whether increased risk of subsequent adverse neonatal outcomes among very preterm singletons is related to ART treatment itself or more attributable to the underlying subfertility [8]. The study using a population cohort approach aims to compare adverse neonatal outcomes among very preterm singletons born after fertility treatment including ART, hyper-ovulation $(\mathrm{HO})$ and artificial insemination (AI) to those born following spontaneous conceptions. We hypothesized that very preterm singletons following fertility treatment have increased risk of morbidity and mortality.

\section{Methods}

Data

This study used data and definitions from the ANZNN data collection. The ANZNN is collected annually from all NICUs in Australia and New Zealand. Liveborn babies included in ANZNN are either born at less than 32 weeks gestation, or weighed less than 1,500 $\mathrm{g}$ at birth, or those who received assisted ventilation or major surgery (surgery that involved opening a body cavity). A research dataset including all liveborn singletons $(N=$ $24,069)$ of $<32$ weeks gestation born between 2000 and 2010 was supplied from ANZNN for this study. Of these, $17696(73.5 \%)$ were with birthweight $<1500 \mathrm{~g}$, 9854 (40.9\%) required assisted ventilation and 1946 (8.1\%) had major surgery.

\section{Main outcome measures}

The primary outcomes are morbidity and mortality before NICU discharge. Outcome measures were categorised into conditions at birth and NICU complications. Conditions at birth include small for gestational age (SGA, $<10^{\text {th }}$ percentile for the gestation), 5 min APGAR score (less than 7 was categorised as moderate/severe depressed), extreme low birth weight (extreme LBW; <1000 g), intubation during resuscitation and presence of congenital abnormalities (defined as structural abnormalities including deformations that are present at birth and diagnosed prior to separation from care). SGA for non-ART singletons were estimated from already published birthweight for gestational age percentile charts $[9,10]$. SGA for ART singletons was estimated using published birthweight percentiles by gestational age for ART births [11]. NICU complications include hyaline membrane disease, necrotizing enterocolitis (NEC), intraventricular haemorrhage, retinopathy of prematurity, major surgery and death.

\section{Comparison group}

Conditions at birth and NICU complications were compared among liveborn singletons by four modes of conceptions flagged the ANZNN database: spontaneous conception (no fertility treatment used for this pregnancy), HO (any hormone therapy used to stimulate ovulation), ART (any method of in-vitro handling oocyte or embryos including in-vitro fertilisation, gamete intrafallopian transfer, zygote intra fallopian transfer) and AI. ANZNN data collection does not have detailed information about the ART fertilisation procedures, fresh or frozen embryos, and the number of embryo transferred and stage of embryo development (blastocyst or cleavage stage). Other study factors include maternal age, ethnicity, gestational age and maternal complications, including pregnancy inducted hypertension in pregnancy (A systolic blood pressure $>140 \mathrm{mmHg}$ and/or diastolic 
blood pressure $>90 \mathrm{mmHg}$, or a rise in systolic blood pressure $>25 \mathrm{mmHg}$ and/or a rise in diastolic blood pressure $>15 \mathrm{mmHg}$ from a reading before conception or in $1^{\text {st }}$ trimester; confirmed by 2 readings $6 \mathrm{~h}$ apart), antepartum haemorrhage (Significant haemorrhage in the time from 20 weeks gestation to the end of second stage of labour) and premature rupture of membranes (Confirmed spontaneous rupture of membranes occurring prior to the onset of labour and before 37 weeks gestation).

\section{Statistical analysis}

Demographics characteristics (maternal age, aboriginal status, gestational age, previous preterm birth and previous perinatal death) and other maternal conditions (premature rupture of membranes, pregnancy inducted hypertension, antepartum haemorrhage and antenatal steroid) were compared among mode of conception and differences in the means and proportions were tested. Analysis of variance was used for continuous variables and Chi-square test was used for categorical variables. Univariate and multivariate binary logistic regression analysis was used to examine the association between mode of conception and various outcome factors. Odds ratio (OR) and adjusted odds ratio (AOR) (adjusted for maternal age, gestational age, ethnicity, previous pre term, previous prenatal death, maternal hypertension, antepartum haemorrhage, PROM and antenatal steroid) and $95 \% \mathrm{CI}$ were calculated. The level of significance was set at 0.05 , and $95 \%$ CIs were used to minimize the risk of chance findings. Statistical Package for Social Sciences (SPSS, Inc., Chicago, IL, USA Version 21) was used for data analysis.

\section{Results}

The information on mode of conception was available for 21,753 (90.4\%) singletons. Among these, 94.4\% (20,530/ 21,753 ) of singletons were born following spontaneous conception, 4.4\% (953/21,753) after ART, $1 \%(216 / 21,753)$ after $\mathrm{HO}, 0.2 \%(54 / 21,753)$ after AI. Figure 1 presents the distribution of gestational age by the mode of conceptions. The proportion of extreme preterm was $26.1 \%$ in AI group, compared to $30.6 \%$ in ART group, $33.7 \%$ in $\mathrm{HO}$ group and $32.9 \%$ in spontaneous conception group.

The average age of mother following ART (34.6 \pm 4.7 years $), \mathrm{AI}(33.3 \pm 4.7$ years $)$ and $\mathrm{HO}(30.2 \pm 4.9$ years $)$ was significantly higher compared to those who conceived spontaneously $(28.9 \pm 6.3$ years $)(p<0.01)$. Similarly, the mean gestational age was significantly different among four groups $(p=0.01)$ (Table 1$)$. Compared to the spontaneously conceived singletons, mothers of ART singletons had higher proportions of pregnancy inducted hypertension and use of antenatal steroids $(p<0.01)$.

Figure 2 shows the number of singletons admitted to NICU by the mode of conceptions over the period of 10 years. NICU admissions for the singletons conceived spontaneously and after ART treatment increased by $11.7 \%$ and $48.8 \%$ respectively from $2001-10$.

The rates of adverse birth outcomes were higher in HO, ART and AI singletons, compared to the spontaneous conception. In the univariate analysis, HO was associated with SGA, and extreme LBW; ART was associated with extreme LBW, intubation during resuscitation and major malformation; and AI was associated with SGA and congenital abnormalities (Table 2). Compared to very preterm singletons conceived spontaneously, the odds of SGA was about 3 times higher for those after AI (AOR 2.98, 95\% CI

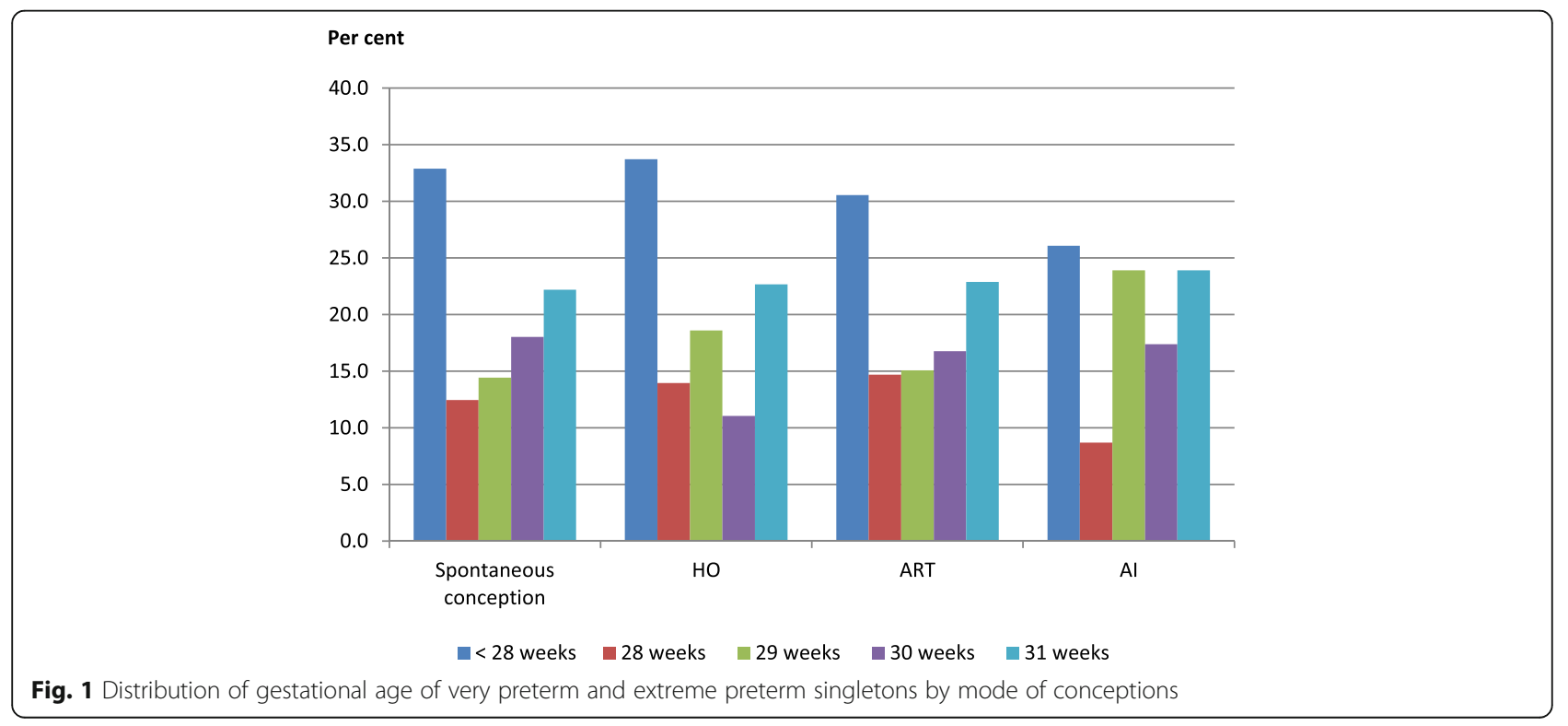


Table 1 Demographics of very preterm singletons by mode of conceptions

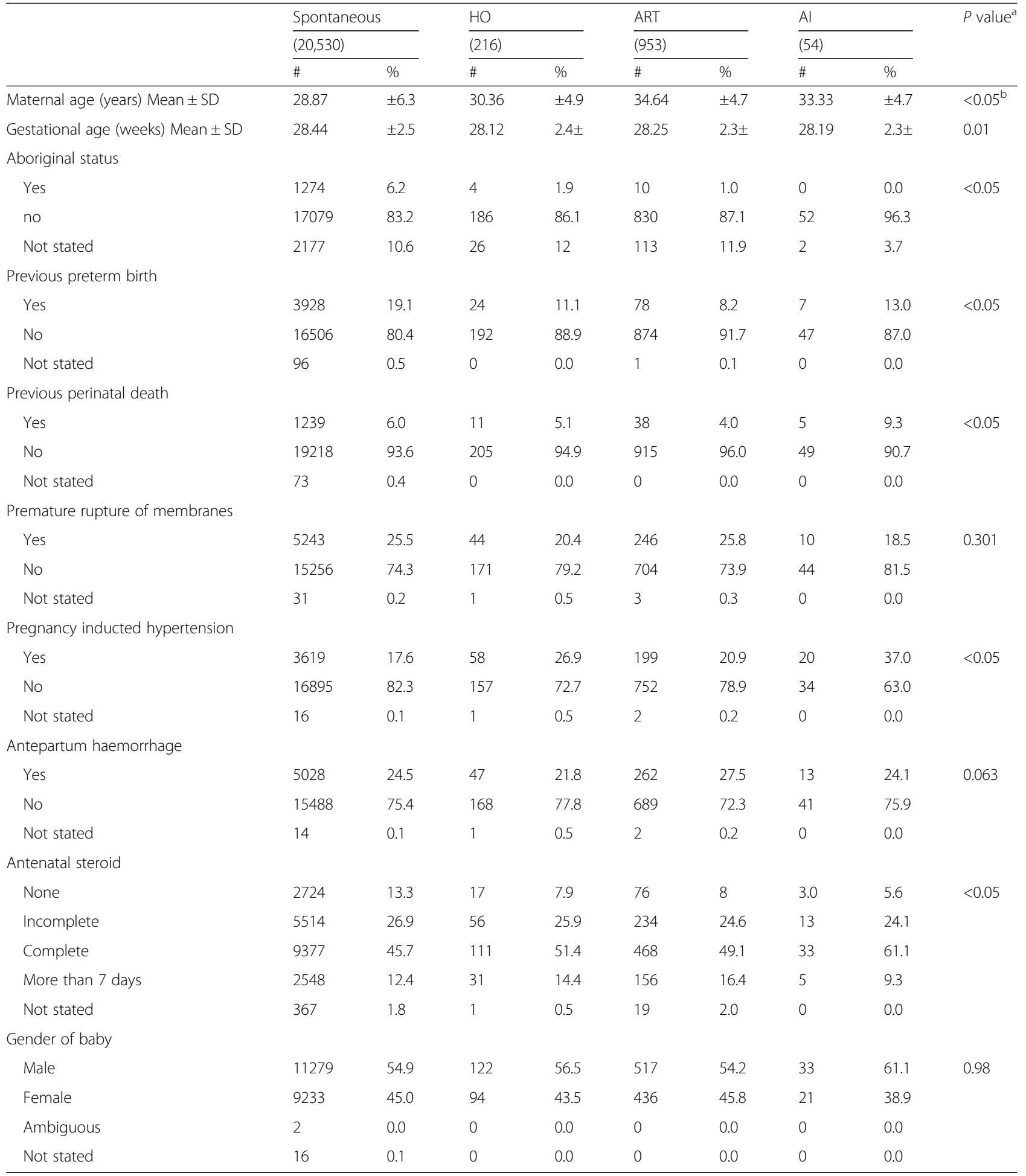

\footnotetext{
${ }^{a}$ chi square test.
}

${ }^{\mathrm{b}}$ Analysis of variance

1.53-5.81) and 1.5 times higher for those after $\mathrm{HO}$ (AOR 1.52 , 95\% CI 1.02-2.67). Similarly, the odds of major abnormalities was 3 times (AOR 3.01, 95\% CI 1.47-6.19) higher for AI singletons and 1.7 times (AOR 1.71, 95\% CI
1.36-2.16) higher for ART singletons than spontaneous singletons. Other birth outcomes were not significantly different between spontaneous conception group and the three fertility treatment groups. 


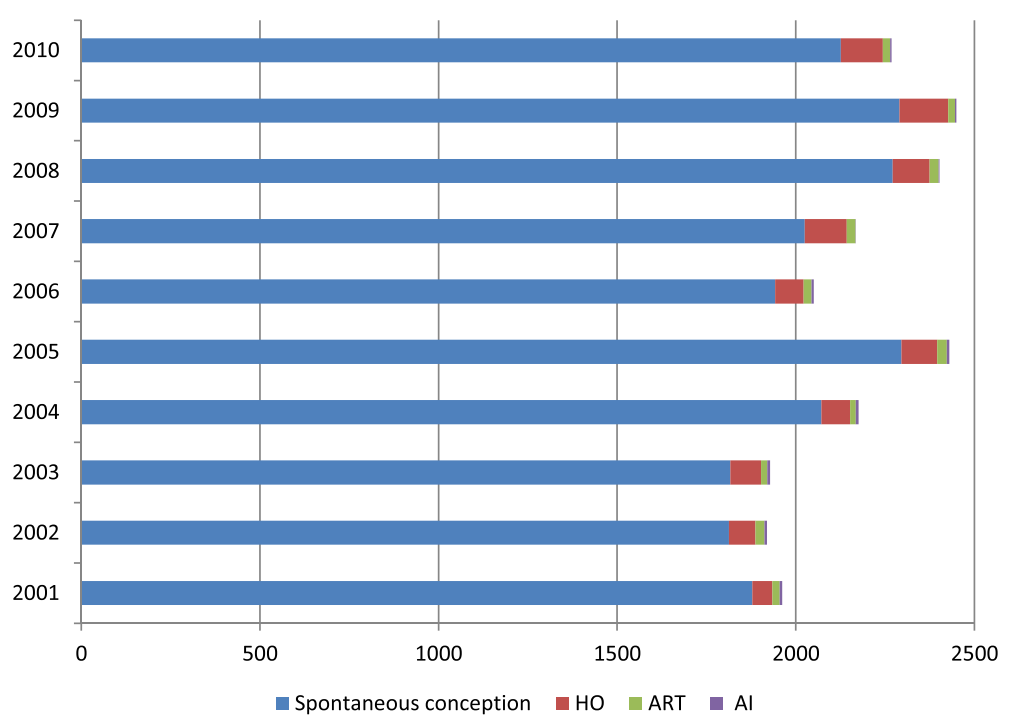

Fig. 2 Number of very preterm and extreme preterm singletons by mode of conceptions 2001-2010

Table 2 Birth conditions of very preterm singletons by mode of conceptions

\begin{tabular}{|c|c|c|c|c|}
\hline & Number & Percent & OR $(95 \% \mathrm{Cl})$ & AOR $(95 \% C l)^{a}$ \\
\hline \multicolumn{5}{|l|}{ Small for gestational age } \\
\hline Spontaneous conception & 1833 & 8.9 & Ref & Ref \\
\hline $\mathrm{HO}$ & 35 & 16.2 & $1.97(1.37-2.84)$ & $1.52(1.02-2.67)$ \\
\hline ART & 102 & 10.7 & $1.22(0.99-1.51)$ & $1.09(0.87-1.38)$ \\
\hline $\mathrm{Al}$ & 16 & 29.6 & $4.29(2.39-7.71)$ & $2.98(1.53-5.81)$ \\
\hline \multicolumn{5}{|c|}{5 min APGAR (Mod/ severe depressed) } \\
\hline Spontaneous conception & 3659 & 18.0 & Ref & Ref \\
\hline $\mathrm{HO}$ & 35 & 16.2 & $0.88(0.61-1.27)$ & $0.78(0.52-1.18)$ \\
\hline ART & 176 & 18.6 & $1.04(0.88-1.23)$ & $1.02(0.85-1.24)$ \\
\hline Al & 10 & 18.5 & $1.04(0.52-2.06)$ & $1.07(0.52-2.22)$ \\
\hline \multicolumn{5}{|c|}{ Extreme Low birth weight $(<1000 \mathrm{~g})$} \\
\hline Spontaneous conception & 6676 & 32.5 & Ref & Ref \\
\hline $\mathrm{HO}$ & 88 & 40.7 & $1.43(1.09-1.87)$ & $1.13(0.72-1.79)$ \\
\hline ART & 351 & 36.8 & $1.21(1.06-1.38)$ & $1.11(0.88-1.40)$ \\
\hline $\mathrm{Al}$ & 22 & 40.7 & $1.43(0.83-2.46)$ & $1.01(0.43-2.42)$ \\
\hline \multicolumn{5}{|l|}{ Intubation during resuscitation } \\
\hline Spontaneous conception & 8405 & 41.0 & Ref & Ref \\
\hline $\mathrm{HO}$ & 101 & 46.8 & $1.26(0.97-1.65)$ & $1.16(0.84-1.60)$ \\
\hline ART & 440 & 46.3 & $1.24(1.09-1.41)$ & $1.11(0.94-1.30)$ \\
\hline Al & 22 & 40.7 & $0.97(0.57-1.70)$ & $0.87(0.46-1.64)$ \\
\hline \multicolumn{5}{|l|}{ Congenital abnormalities } \\
\hline Spontaneous conception & 1197 & 6.0 & Ref & Ref \\
\hline $\mathrm{HO}$ & 10 & 4.9 & $0.80(0.42-1.51)$ & $0.80(0.42-1.52)$ \\
\hline ART & 93 & 10.1 & $1.75(1.40-2.19)$ & $1.71(1.36-2.16)$ \\
\hline $\mathrm{Al}$ & 9 & 16.7 & $3.12(1.52-6.40)$ & $3.01(1.47-6.19)$ \\
\hline
\end{tabular}

${ }^{a}$ Adjusted for maternal age, gestational age, ethnicity, previous pre term, previous prenatal death, maternal hypertension, antepartum haemorrhage, premature rupture of membranes and antenatal steroid

Significant results are in bold 
The multivariate analysis shows that very preterm singletons born after ART have 43\% higher odds of having NEC (AOR 1.43, 95\% CI 1.04-1.97) and 71\% higher odds of having major surgery (AOR 1.71, 95\% CI 1.372.13) compared to those conceived spontaneously. Data stratification shows that major surgery was closely related to congenital abnormalities. Major surgery was reported in $33 \%$ and $11 \%$ of ART singletons with and without congenital abnormalities respectively ( $p$ value $<0.05)$. Other NICU outcomes were not significantly different spontaneous conception group and the three fertility treatment groups (Table 3).

\section{Discussion}

This bi-national population study showed that the rates of some adverse neonatal outcomes are significantly increased among the very preterm singletons following fertility treatment. Compared to the spontaneous conception group, ART and AI groups had 1.7 times and 3.0 times increased odds of major malformation. Very preterm singletons following $\mathrm{HO}$ and $\mathrm{AI}$ had 1.5 times and 3.0 times increased odds of SGA than spontaneous conception group. ART is associated with $43 \%$ and $71 \%$ higher odds of NEC and major surgery compared to spontaneous conception group.

Table 3 NICU outcomes of very preterm singletons by mode of conceptions

\begin{tabular}{|c|c|c|c|c|}
\hline & Number & Percent & OR $(95 \% \mathrm{Cl})$ & AOR $(95 \% C l)^{a}$ \\
\hline \multicolumn{5}{|l|}{ Hyaline membrane disease } \\
\hline Spontaneous conception & 14574 & 71.9 & Ref & Ref \\
\hline $\mathrm{HO}$ & 154 & 72.0 & $1.00(0.74-1.36)$ & $0.87(0.62-1.21)$ \\
\hline ART & 724 & 76.9 & $1.30(1.11-1.52)$ & $1.18(0.99-1.40)$ \\
\hline Al & 38 & 72.1 & $0.93(0.52-1.67)$ & $0.75(0.41-1.42)$ \\
\hline \multicolumn{5}{|l|}{ Necrotizing enterocolitis } \\
\hline Spontaneous conception & 817 & 4.0 & Ref & Ref \\
\hline $\mathrm{HO}$ & 3 & 1.4 & $0.34(0.11-1.04)$ & $0.33(0.10-1.05)$ \\
\hline ART & 49 & 5.2 & $1.30(0.97-1.75)$ & $1.43(1.04-1.97)$ \\
\hline Al & 2 & 3.7 & $0.92(0.22-3.80)$ & $0.85(0.20-3.60)$ \\
\hline \multicolumn{5}{|l|}{ Intra ventricular haemorrhage } \\
\hline Spontaneous conception & 4327 & 23.1 & Ref & Ref \\
\hline $\mathrm{HO}$ & 53 & 26.0 & $1.17(0.85-1.60)$ & $1.23(0.86-1.75)$ \\
\hline ART & 229 & 25.6 & $1.14(0.98-1.33)$ & $1.20(1.00-1.43)$ \\
\hline Al & 12 & 23.1 & $0.99(0.52-1.90)$ & $1.21(0.61-2.40)$ \\
\hline \multicolumn{5}{|l|}{ Retinopathy of prematurity } \\
\hline Spontaneous conception & 3896 & 26.6 & Ref & Ref \\
\hline $\mathrm{HO}$ & 49 & 31.6 & $1.27(0.91-1.79)$ & $1.04(0.70-1.52)$ \\
\hline ART & 187 & 27.2 & $1.03(0.87-1.22)$ & $1.00(0.82-1.24)$ \\
\hline $\mathrm{Al}$ and other & 10 & 23.3 & $0.83(0.41-1.70)$ & $0.99(0.44-2.17)$ \\
\hline \multicolumn{5}{|l|}{ Major surgery } \\
\hline Spontaneous conception & 1642 & 8.1 & Ref & Ref \\
\hline $\mathrm{HO}$ & 23 & 10.7 & $1.37(0.89-2.11)$ & $1.27(0.79-2.02)$ \\
\hline ART & 122 & 12.9 & $1.70(1.39-2.06)$ & $1.71(1.37-2.13)$ \\
\hline $\mathrm{Al}$ & 6 & 11.1 & $1.43(0.61-2.34)$ & $1.00(0.389-2.60)$ \\
\hline \multicolumn{5}{|l|}{ Deaths } \\
\hline Spontaneous conception & 1852 & 9.0 & Ref & Ref \\
\hline $\mathrm{HO}$ & 20 & 9.3 & $1.02(0.65-1.63)$ & $0.67(0.38-1.18)$ \\
\hline ART & 98 & 10.3 & $1.15(0.93-1.43)$ & $1.11(0.86-1.42)$ \\
\hline $\mathrm{Al}$ & 9 & 16.7 & $2.01(0.98-4.13)$ & $2.10(0.93-4.76)$ \\
\hline
\end{tabular}

${ }^{a}$ Adjusted for maternal age, gestational age, ethnicity, previous pre term, previous prenatal death, maternal hypertension, antepartum haemorrhage, premature rupture of membranes and antenatal steroid

Significant results are in bold 
The literature shows that fertility treatments including ART, AI, HO and use of Clomiphene are associated with increased risk of adverse pregnancy and perinatal outcomes [12]. Very preterm and preterm birth are such adverse perinatal outcomes associated fertility treatment, and are leading causes of other morbidity and mortality $[13,14]$. We selected very preterm singletons as our study population which reduced the confounding and interaction effects between the fertility treatment and adverse perinatal outcomes due to multiple pregnancies and prematurity. Agreed with the literature, our findings suggested that very preterm singletons following ART and other fertility treatment are at increased risk of fetal and neonatal outcomes [15-18].

A number of studies reported higher incidence of low birthweight among births following fertility treatment than spontaneous births $[6,19-22]$. Since our study population was limited to very preterm singletons, the low birthweight is not a measure relevant to our study population. Instead, we used SGA to measure birthweight outcomes. Babies are SGA if their weights are below the 10th percentile for their gestational ages. Although the majority babies born SGA catch up in growth at 2 years old, SGA babies are at increased risk of morbidity and mortality [7]. Apart from genetic reasons, SGA is related to fetal, maternal and placental conditions. Subfertility, one of the maternal conditions is associated with increased risk of SGA [23]. Since all couples who access ART treatment have some level of subfertility, they are more likely to have a SGA baby [17]. Zhu and colleagues also reported a high rate of SGA in sub-fertile women regardless of ART treatment [23]. Even for very preterm singletons, those born to mothers following fertility treatment, an indicator of subfertility, have a higher rate of SGA than those following spontaneous conceptions.

Congenital anomaly is the one of the leading causes of neonatal death among the preterm babies [24]. Many studies have reported an increased rate of congenital anomalies among births following fertility treatment compared to spontaneous births $[18,25,26]$, with the prevalence of congenital anomalies ranges from 4-9\% among ART births according to various studies [12, 17, 27], and $4-6 \%$ in general population [28, 29]. Even though our rates are comparable with other published studies, it should be interpreted with cautions as we only included very preterm births in this study. Increase risk of congenital abnormality may be due to generally increased risk of congenital amorality in ART group or due to shift of gestational duration toward lower values among a normal rate of congenital amorality. Moreover, congenital anomalies may be on the casual pathway to low birth weight or preterm birth [30,31].

Presence of congenital abnormalities is one of the major causes of surgery and other adverse neonatal outcomes in the neonatal period [32]. The most common reasons for major surgery in our study include vascular system (418 cases), skeletal system (151 cases), gastrointestinal (146 cases), genital tract (136 cases) and respiratory (105 cases). The higher rate of major surgery among ART singletons in our study is likely due to associated congenital abnormalities. Rates of major surgery were significantly in ART singletons with congenital abnormalities, compared to ART singletons without congenital abnormalities ( $p$ value $<0.05)$. Similarly we need to assume that a chain of event might happen and in most cases birth conditions are related to the common NICU outcomes including NEC, intraventricular haemorrhage, hyaline membrane disease and retinopathy of prematurity among the very preterm babies [24]. Although the rates of all conditions were high in the ART group, only NEC was significantly associated with the ART in this study.

Necrotizing Enterocolitis is one of the most common severe diseases among preterm births, with high morbidity and mortality. Yee and colleagues suggested that the mortality for NEC can be up to $50 \%$ and $20-40 \%$ cases may need surgical treatment [33]. The rates of NEC in our study were $5.2 \%$ among ART and $4.0 \%$ among spontaneous conceived very preterm singletons. These are within the range between $3 \%$ and 15\% reported by other studies [34]. The increase rate of NEC and very preterm ART singletons in our study remains unclean as the cause necrotizing enterocolitis is incompletely understood. Neu and Walker suggested that the cause of NEC is multifactorial, but it is preventable by withholding enteral feedings, using enteral antibiotics, feeding with expressed breast milk, and administering probiotic agents [35].

Death rates in ART treatment groups were high in our study, compared to the spontaneous conception group, however the difference was not statistically significant. In a previous NICU study in Australia, low mortality was observed in the ART twins and triplets compare to spontaneously conceived twins and triplets and authors attributed it "protective effect" to the "dichorionic pregnancies" and specialized care offered to the ART mothers [20]. Another study reported low rate of death among the babies born after the ART treatment and authors attributed it to the single embryo transfer practices and comparison of ART healthy babies with sick non ART babies [24]. However both these studies included multiple pregnancies in the analysis and there is ample of evidence suggests that ART singletons have high mortality compared to non-ART singletons [21].

Survival rates of the very preterm babies have been improved in the last few decades due to increase use of ventilator support, steroids and surfactants [36 37]. However the outcome is still poor among the babies 
born after the fertility treatment. It is not clear whether this is due to complication of treatment such as congenital abnormalities or due to maternal conditions such as pregnancy induced hypertension. These babies are at risk of long term neurological and behavioural complications which are not well studied [38]. The outcome in the very preterm singletons also may be different as it is associated with the gestational age. Among the preterm babies, the mortality is generally very high among the those born at 23 weeks (84\%) compared to those born at 28 week (13\%) [39]. The potential risk of very preterm birth and subsequent neonatal morbidity and mortality should be explained to the women undergoing ART treatment.

There are some limitations of this study, which are important while interpreting the results. In the ANZNN database four categories are mentioned under the flag "Assisted conception": spontaneous conception, HO, ART and AI. It is possible that some HO and AI singletons were misreported into spontaneous conception group given the small number of $\mathrm{HO}$ and $\mathrm{AI}$ singletons were identified in this study. However, we are unable to track the assisted conception from other records. Similarly we are unable to track the pregnancies characterises including gestational sacs and fetal hearts. It is suggested that singletons born as a result of vanish twins/triples have increased risk of adverse perinatal outcomes those born with initial one gestational sac/fetal heart (Wang et al. 2009). This is especially relavent to HO and ART singletons where multiple gestational sacs pregnancies are prevalent $[12,14]$.

ART included complex procedures such as oocyte collection, ICSI procedure, cleavage stage transfer, frozen embryo transfer, and number of embryos transferred. Detailed information on types of cycle, ART procedures, and embryo transfers which may be associated with adverse maternal and fetal outcomes is not available in the database [40, 41]. For example high rate of congenital abnormalities are reported after the ICSI procedure [12] and cleavage stage transfer [42]. Perinatal outcomes are usually favourable following frozen embryo transfers than fresh embryo transfers [13, 43]. Similarly, double embryo transfer is related to multiple birth [44] and multiple births had higher chances of congenital abnormalities than the singletons [45]. Compared to the single embryo transfers, 1.5 fold increase in fetal death has been reported for births following double embryo transfers [14].

Another limitation of this study was restricting analysis to only extreme preterm and very ( $<32$ weeks) births, which limits the study generalisation to all preterm births. ANZNN data collection includes births of gestational age $<32$ weeks in Australia and New Zealand, however the evidence suggests that the rate of preterm in the developed countries are mainly increased for the moderate preterm birth (32-36 weeks gestation) [46]. As ANZNN only includes babies of birth weight $<1,500 \mathrm{~g}$, many LBW babies may not be admitted to NICU and were not included from the study. Comparison between babies of birth weight $<1,500 \mathrm{~g}$ and those of birth weight $1500-2499 \mathrm{~g}$ is important since the later have less complications compared to very preterm babies. Another limitation of this study is that we are unable to identify women who have a history of subfertility but conceived spontaneously. These women were included in the spontaneous conception group although they were inherently different from women without history of infertility [47, 48]. Previous studies also show that maternal and childhood complications are more common in subfertile women compared to fertile women [49-51]. This indicates that some biological factors may play a role however there is limited evidence.

Our multivariate analysis was adjusted for maternal age, gestational age, ethnicity, previous pre term, previous prenatal death, maternal hypertension, antepartum haemorrhage, PROM and antenatal steroid. The residual confounding may exist as we were unable to adjust factors such as maternal smoking, BMI, location and size of NICU, method of delivery and parental social-economic status. Moreover, increase risk of congenital abnormality and other morbidities after fertility treatments in NICU setting may not be generalised to the all babies born after fertility treatment. We only examined morbidity and mortality among cases admitted to NICUs. Fetal deaths and terminations due to prenatally diagnosed congenital abnormality are not included. Finally the comparison was made between spontaneous conceived singletons and those following ART, HO and AI. We did not make comparison across fertility treatment groups due to small sample size in $\mathrm{HO}$ and AI groups. Further studies need be conducted by directly comparing outcomes in sub-fertile/infertile women conceived with or without fertility treatment and type of fertility treatment $[52,53]$.

\section{Conclusions}

Very preterm ( $<32$ weeks gestational age) singletons following $\mathrm{HO}, \mathrm{ART}$ and AI had higher rates of some neonatal morbidity than spontaneous singletons. Compared to the spontaneous conception group, risk of birth defects significantly increases after ART and AI; the risk of morbidities increases after ART, HO and AI. Preconception planning should include comprehensive information about the benefits and risks of fertility treatment on the neonatal outcomes. 


\section{Abbreviations}

Al: Artificial insemination; ANZNN: Australian and New Zealand Neonatal Network; AOR: Adjusted odds ratio; ART: Assisted reproductive technology; Cl: Confidence interval; HO: Hyper-ovulution; LBW: Low birth weight; NICU: Neonatal Intensive Care Unit; OR: Odds ratio; SGA: Small for gestational age

\section{Acknowledgement}

We acknowledge the Advisory Council Members of ANZNN: Ross Haslam* Chair of the Executive Committee; Flinders Medical Centre, SA: Peter Marshall. Gosford University Hospital, QLD: Peter Schmidt. Gosford District Hospital, NSW: Adam Buckmaster*. John Hunter Hospital, NSW: Paul Craven, Koert de Waal*. King Edward Memorial and Princess Margaret Hospitals, WA: Karen Simmer, Andy Gill*, Jane Pillow*. Liverpool Hospital, NSW: Jacqueline Stack. Mater Mothers' Hospital, QLD: Lucy Cooke. Mercy Hospital for Women, VIC: Dan Casalaz, Jim Holberton*. Monash Medical Centre, VIC: Charles Barfield,. Nepean Hospital, NSW: Lyn Downe Vijay Shingde. Newborn Emergency Transport Service (VIC): Michael Stewart. NSW Newborn and Pregnancy Services Network: Barbara Bajuk*. NSW Newborn \& Paediatric Emergency Transport Service: Andrew Berry. Royal Children's Hospital, VIC: Rod Hunt. Royal Darwin Hospital, NT: Charles Kilburn. Royal Hobart Hospital, Tasmania: Tony De Paoli. Royal Hospital for Women, NSW: Kei Lui*. Royal North Shore Hospital, NSW: Mary Paradisis. Royal Prince Alfred Hospital, NSW: Ingrid Rieger, Shelley Reid*. Royal Brisbane and Women's Hospital, QLD: David Cartwright, Pieter Koorts. Royal Women's Hospital, VIC: Carl Kuschel, Lex Doyle. Sydney Children's Hospital, NSW: Andrew Numa. The Canberra Hospital, ACT: Hazel Carlisle. The Children's Hospital at Westmead, NSW: Nadia Badawi, Robert Halliday. The Townsville Hospital, QLD: Guan Koh*. Western Australia Neonatal Transport Service: Steven Resnick. Westmead Hospital, NSW: Melissa Luig. Women's \& Children's Hospital, SA: Chad Andersen. National Perinatal Epidemiology and Statistics Unit, University of New South Wales: Georgina Chambers*. New Zealand: Christchurch Women's Hospital: Adrienne Lynn, Brian Darlow. Dunedin Hospital: Roland Broadbent*. Middlemore Hospital: Lindsay Mildenhall. Auckland City Hospital: Malcolm Battin. North Shore and Waitakere Hospitals: Jutta van den Boom* Waikato Hospital: David Bourchier, Lee Carpenter*. Wellington Women's Hospital: Vaughan Richardson. Singapore: KK Women's and Children's Hospital, Singapore: Victor Samuel Rajadurai*

* denotes the ANZNN Executive Committee.

\section{Funding}

There is no specific funding related to this research.

\section{Availability of data and material}

The datasets generated during and/or analysed during the current study are available in the Australian \& New Zealand Neonatal Network (ANZNN) repository, https://www.anznn.net/.

\section{Authors' contributions}

AW designed the study, prepared the data, drafted the manuscript, and approved the final manuscript as submitted. AC prepared the data, carried out the initial analyses, drafted the manuscript and approved the final manuscript as submitted. $K L$ reviewed and revised the manuscript, and approved the final manuscript as submitted. ES conceptualised and designated the study, reviewed and revised the manuscript, and approved the final manuscript as submitted.

\section{Competing interests}

The authors declare that they have no competing interests

\section{Consent for publication}

Not applicable

\section{Ethics approval and consent to participate}

Ethics approval for this study was granted by the Human Research Ethics Advisory (HREA Social/health) Panel of the University of New South Wales Australia (HREA 9-13-002). Use of ANZNN data was approved by the ANZNN committee.

\section{Author details}

${ }^{1}$ Faculty of Health, University of Technology Sydney, PO Box 123, Broadway, NSW 2007, Australia. ${ }^{2}$ School of Public Health and Community Medicine, University of New South Wales, Sydney, NSW 2031, Australia. ${ }^{3}$ School of
Women's and Children's Health, University of New South Wales, Sydney, NSW 2031, Australia.

Received: 23 July 2016 Accepted: 21 January 2017

Published online: 02 February 2017

\section{References}

1. Hilder LZZ, Parker M, Jahan S, Chambers GM. 014. Australia's mothers and babies 2012. Perinatal statistics series no. 30. Cat. no. PER 69. Canberra: AlHW; 2014

2. Blencowe $H$, Cousens $S$, Oestergaard MZ, Chou D, Moller AB, Narwal R, et al. National, regional, and worldwide estimates of preterm birth rates in the year 2010 with time trends since 1990 for selected countries: a systematic analysis and implications. Lancet. 2012;379(9832):2162-72.

3. Kramer MS, Demissie K, Yang H, Platt RW, Sauve R, Liston R. The contribution of mild and moderate preterm birth to infant mortality. Fetal and Infant Health Study Group of the Canadian Perinatal Surveillance System. JAMA. 2000;284(7):843-9.

4. Chow SSW. Report of the Australian and New Zealand Neonatal Network 2012. Sydney: ANZNN; 2014.

5. Beck S, Wojdyla D, Say L, Betran AP, Merialdi M, Requejo JH, et al. The worldwide incidence of preterm births: a systematic review of maternal mortality and morbidity. Bulletin World Health Organization. 2010;88:31-8.

6. Nyirati I, Orvos H, Bártfai G, Kovács L. latrogenic multiple pregnancy: Higher risk than a spontaneous one? J Reprod Med. 1997;42(11):695-8

7. Battaglia FC, Lubchenco LO. A practical classification of newborn infants by weight and gestational age. J Pediatr. 1967;71(2):159-63.

8. Thomson F, Shanbhag S, Templeton A, Bhattacharya S. Obstetric outcome in women with subfertility. Bjog. 2005;112(5):632-7.

9. Dobbins TA, Sullivan EA, Roberts CL, Simpson JM. Australian national birthweight percentiles by sex and gestational age, 1998-2007. Med J Aust. 2012;197(5):291.

10. Roberts C, Lancaster P. National birthweight percentiles by gestational age for twins born in Australia. J Paediatr Child Health. 1999;35(3):278-82.

11. Li Z, Wang YA, Ledger W, Sullivan EA. Birthweight percentiles by gestational age for births following assisted reproductive technology in Australia and New Zealand, 2002-2010. Hum Reprod. 2014;29(8):1787-800.

12. Davies MJ, Moore VM, Willson KJ, Van Essen P, Priest K, Scott H, et al. Reproductive technologies and the risk of birth defects. N Engl J Med. 2012; 366(19):1803-13

13. Wang YA, Sullivan EA, Black D, Dean J, Bryant J, Chapman M. Preterm birth and low birth weight after assisted reproductive technology-related pregnancy in Australia between 1996 and 2000. Fertil Steril. 2005;83(6): 1650-8.

14. Wang YA, Sullivan EA, Healy DL, Black DA. Perinatal outcomes after assisted reproductive technology treatment in Australia and New Zealand: single versus double embryo transfer. Med J Aust. 2009;190(5):234-7.

15. Hansen M, Bower C, Milne E, Klerk N, Kurinczuk J. Assisted reproductive technologies and birth outcomes: overview of recent systematic reviews. Reprod Fertil Dev. 2005;17(3):329-33.

16. Koivurova S, Hartikainen A-L, Gissler M, Hemminki E, Sovio U, Järvelin M-R. Neonatal outcome and congenital malformations in children born after invitro fertilization. Hum Reprod. 2002;17(5):1391-8.

17. Bower C, Hansen M. Assisted reproductive technologies and birth outcomes: overview of recent systematic reviews. Reprod Fertil Dev. 2005 17(3):329-33.

18. Halliday JL, Ukoumunne OC, Baker HW, Breheny S, Jaques AM, Garrett C, et al. Increased risk of blastogenesis birth defects, arising in the first 4 weeks of pregnancy, after assisted reproductive technologies. Hum Reprod. 2010; 25(1):59-65. doi:10.1093/humrep/dep364.

19. Pandian Z, Bhattacharya S, Templeton A. Review of unexplained infertility and obstetric outcome: a 10 year review. Hum Reprod. 2001;16(12):2593-7.

20. Garg P, Abdel-Latif ME, Bolisetty S, Bajuk B, Vincent T, Lui K. Perinatal characteristics and outcome of preterm singleton, twin and triplet infants in NSW and the ACT, Australia (1994-2005). Arch Dis Child Fetal Neonatal Ed. 2010;95(1):10

21. Helmerhorst FM, Perquin DA, Donker D, Keirse MJ. Perinatal outcome of singletons and twins after assisted conception: a systematic review of controlled studies. BMJ. 2004:328(7434):261.

22. Jackson RA, Gibson KA, Wu YW, Croughan MS. Perinatal outcomes in singletons following in vitro fertilization: a meta-analysis. Obstet Gynecol. 2004;103(3):551-63. 
23. Zhu JL, Obel C, Bech BH, Olsen J, Basso O. Infertility, infertility treatment and fetal growth restriction. Obstet Gynecol. 2007;110(6):1326.

24. Feng Y, Abdel-Latif ME, Bajuk B, Lui K, Oei JL. Causes of death in infants admitted to Australian neonatal intensive care units between 1995 and 2006. Acta Paediatr. 2013;102(1):1

25. Kallen B, Finnstrom O, Nygren KG, Olausson PO. In vitro fertilization (IVF) in Sweden: infant outcome after different IVF fertilization methods. Fertil Steril. 2005;84(3):611-7.

26. Hansen M, Bower C, Milne E, de Klerk N, Kurinczuk JJ. Assisted reproductive technologies and the risk of birth defects-a systematic review. Hum Reprod. 2005;20(2):328-38.

27. Kallen B, Finnstrom O, Nygren KG, Olausson PO. In vitro fertilization (IVF) in Sweden: risk for congenital malformations after different IVF methods. Birth Defects Research. 2005;73(3):162-9.

28. Gibson CS vEP, Scott H, Baghurst P, Chan A, Scheil W. Annual Report of the South Australian Birth Defects Register, incorporating the 2007 Annual Report of Prenatal Diagnosis in South Australia. Adelaide: SA Birth Defects Register, Children, Youth and Women's Health Service; 2007.

29. Bower C, Rudy E, Callaghan A, Quick J, Cosgrove P. Report of the Birth Defects Registry of Western Australia 1980-2009. 2010.

30. Honein MA, Kirby RS, Meyer RE, Xing J, Skerrette NI, Yuskiv N, et al. The association between major birth defects and preterm birth. Matern Child Health J. 2009;13(2):164-75.

31. Mili F, Edmonds LD, Khoury MJ, McClearn AB. Prevalence of birth defects among low-birth-weight infants: a population study. Am J Dis Child. 1991 . 145(11):1313-8

32. Van den Berg BJ, Yerushalmy J. The relationship of the rate of intrauterine growth of infants of low birth weight to mortality, morbidity, and congenital anomalies. J Pediatr. 1966;69(4):531-45.

33. Yee WH, Soraisham AS, Shah VS, Aziz K, Yoon W, Lee SK. Incidence and timing of presentation of necrotizing enterocolitis in preterm infants. Pediatrics. 2012;129(2):e298-304.

34. Wolf EJ, Vintzileos AM, Rosenkrantz TS, Rodis JF, Lettieri L, Mallozzi A. A comparison of pre-discharge survival and morbidity in singleton and twin very low birth weight infants. Obstet Gynecol. 1992;80(3 Pt 1):436-9.

35. Neu J, Walker WA. Necrotizing enterocolitis. N Engl J Med. 2011;364(3):255-64.

36. Blickstein I, Shinwell ES, Lusky A, Reichman B. Plurality-dependent risk of respiratory distress syndrome among very-low-birth-weight infants and antepartum corticosteroid treatment. Am J Obstet Gynecol. 2005;192(2): 360-4.

37. Saigal S, Doyle LW. An overview of mortality and sequelae of preterm birth from infancy to adulthood. Lancet. 2008;371(9608):261-9.

38. Msall ME, Park JJ. The spectrum of behavioral outcomes after extreme prematurity: regulatory, attention, social, and adaptive dimensions. Semin Perinatol. 2008;32(1):42-50

39. Synnes AR, Ling EW, Whitfield MF, Mackinnon M, Lopes L, Wong G, et al. Perinatal outcomes of a large cohort of extremely low gestational age infants (twenty-three to twenty-eight completed weeks of gestation). J Pediatr. 1994;125(6):952-60.

40. Wang JX, Norman RJ, Kristiansson P. The effect of various infertility treatments on the risk of preterm birth. Hum Reprod. 2002;17(4):945-9.

41. Shih W, Rushford DD, Bourne H, Garrett C, McBain JC, Healy DL, et al. Factors affecting low birthweight after assisted reproduction technology: difference between transfer of fresh and cryopreserved embryos suggests an adverse effect of oocyte collection. Hum Reprod. 2008;23(7):1644-53.

42. Wang YA, Kovacs G, Sullivan EA. Transfer of a selected single blastocyst optimizes the chance of a healthy term baby: a retrospective population based study in Australia 2004-2007. Hum Reprod. 2010;25(8):1996-2005.

43. Maheshwari A, Bhattacharya S. Elective frozen replacement cycles for all: ready for prime time? Hum Reprod. 2013;28(1):6-9.

44. Kjellberg AT, Carlsson P, Bergh C. Randomized single versus double embryo transfer: obstetric and paediatric outcome and a cost-effectiveness analysis. Hum Reprod. 2006;21(1):210-6

45. Wennerholm U-B, Bergh C, Hamberger L, Lundin K, Nilsson L, Wikland M, et al. Incidence of congenital malformations in children born after ICSI. Hum Reprod. 1999;15(4):944-8.

46. Martin JA, Hamilton BE, Sutton PD, Ventura SJ, Menacker F, Munson ML. Births: final data for 2003. Natl Vital Stat Rep. 2005:54(2):1-116.

47. Lisonkova S, Janssen PA, Sheps SB, Lee SK, Dahlgren L. The effect of maternal age on adverse birth outcomes: does parity matter? J Obstet Gynaecol Can. 2010;32(6):541-8.
48. Fretts RC. Etiology and prevention of stillbirth. Am J Obstet Gynecol. 2005 193(6):1923-35.

49. Tandberg A, Bjorge T, Nygard O, Bordahl PE, Skjaerven R. Trends in incidence and mortality for triplets in Norway 1967-2006: the influence of assisted reproductive technologies. Bjog. 2010;117(6):667-75.

50. Pelkonen S, Koivunen R, Gissler M, Nuojua-Huttunen S, Suikkari AM, HydenGranskog C, et al. Perinatal outcome of children born after frozen and fresh embryo transfer: the Finnish cohort study 1995-2006. Hum Reprod. 2010; 25(4):914-23.

51. Schieve LA, Cohen B, Nannini A, Ferre C, Reynolds MA, Zhang Z, et al. A population-based study of maternal and perinatal outcomes associated with assisted reproductive technology in Massachusetts. Matern Child Health J. 2007;11(6):517-25

52. Basso O, Olsen J. Subfecundity and neonatal mortality: longitudinal study within the Danish national birth cohort. BMJ. 2005;330(7488):393-4.

53. Barnhart KT. Assisted reproductive technologies and perinatal morbidity: interrogating the association. Fertil Steril. 2013;99(2):299-302.

\section{Submit your next manuscript to BioMed Central and we will help you at every step:}

- We accept pre-submission inquiries

- Our selector tool helps you to find the most relevant journal

- We provide round the clock customer support

- Convenient online submission

- Thorough peer review

- Inclusion in PubMed and all major indexing services

- Maximum visibility for your research

Submit your manuscript at www.biomedcentral.com/submit
C) Biomed Central 